\title{
A Summary of the Results Obtained in the LDRD Project "Interaction of a Magnetized Plasma with Structured Surfaces - From Fusion Devices to Spacecraft"
}

\author{
R. H. Cohen, G. D. Porter, D. D. Ryutov
}

February 23, 1999

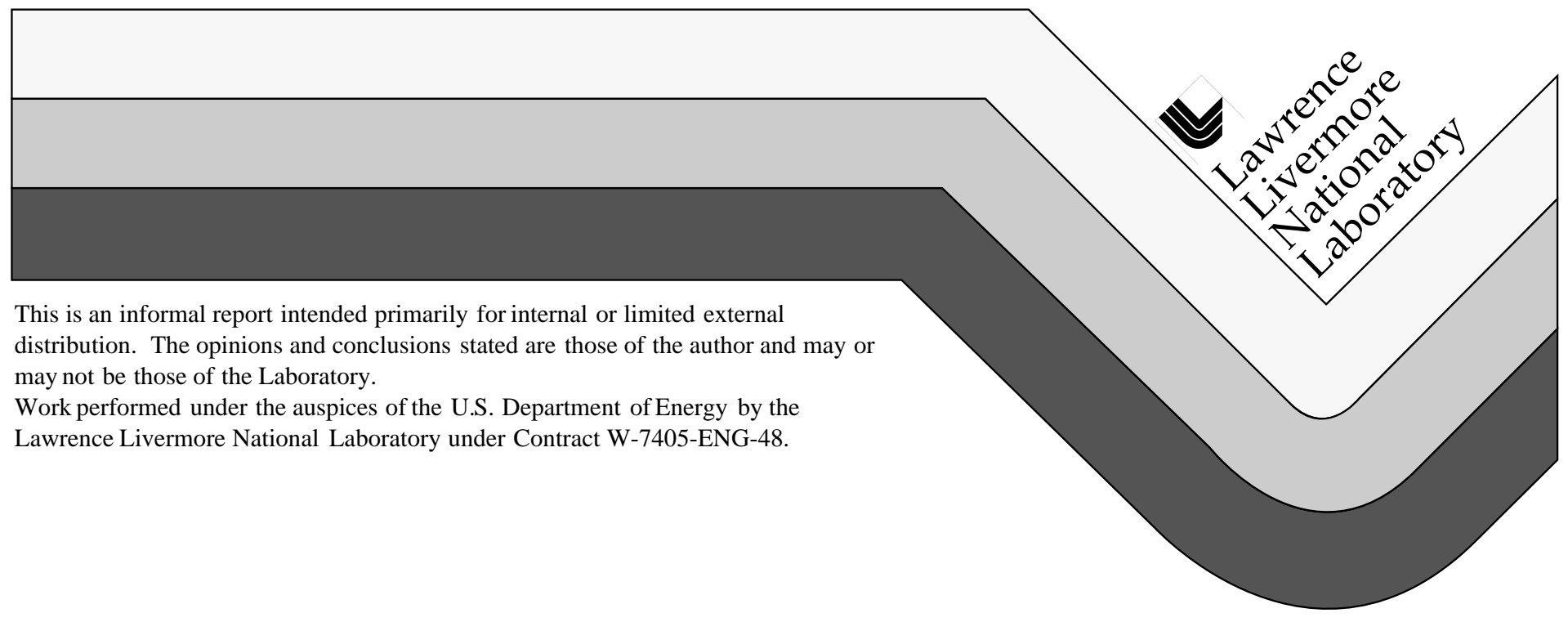




\section{DISCLAIMER}

This document was prepared as an account of work sponsored by an agency of the United States Government. Neither the United States Government nor the University of California nor any of their employees, makes any warranty, express or implied, or assumes any legal liability or responsibility for the accuracy, completeness, or usefulness of any information, apparatus, product, or process disclosed, or represents that its use would not infringe privately owned rights. Reference herein to any specific commercial product, process, or service by trade name, trademark, manufacturer, or otherwise, does not necessarily constitute or imply its endorsement, recommendation, or favoring by the United States Government or the University of California. The views and opinions of authors expressed herein do not necessarily state or reflect those of the United States Government or the University of California, and shall not be used for advertising or product endorsement purposes.

This report has been reproduced directly from the best available copy.

Available to DOE and DOE contractors from the Office of Scientific and Technical Information P.O. Box 62, Oak Ridge, TN 37831

Prices available from (423) 576-8401

Available to the public from the National Technical Information Service

U.S. Department of Commerce 5285 Port Royal Rd. Springfield, VA 22161 


\title{
A summary of the results obtained in the LDRD project "Interaction of a Magnetized Plasma with Structured Surfaces-From Fusion Devices to Spacecraft" (LDRD 98-LW-023)
}

\author{
R.H. Cohen, G.D. Porter, D.D. Ryutov (PI)
}

Our work was directed towards developing a basic understanding of a new class of phenomena: effects of surface structure on the processes in a magnetized plasma near surfaces and at some distances for them. The main results of this study have been published in References [1]-[7].

The surface structures can be of various kinds: topographic features ranging from smooth "waviness" to a coarse "roughness," non-uniformities of the secondary emission coefficient, dielectric impregnations into conducting surface, etc. The expected effects are strongest when the magnetic field forms a shallow angle with the surface. The current and future applications of this new branch of plasma physics include fusion devices, gasdischarge and plasma-processing devices, large spacecraft, and physical phenomena in the vicinity of celestial bodies without atmospheres (like, e.g., the Moon).

Our theoretical work is covered by References [1,2] and by parts of References [3, 7]. We have developed a methodology that allows one to study in a unified way effects of rough surfaces with arbitrary scales of topographic features, from sizes exceeding the ion gyro-radius [1], to sizes much below the electron gyro-radius [2,7], in the most interesting case of a grazing magnetic field. The results can be presented in a dimensionless form, so that they would be equally applicable to the micrometer-scale roughness of the divertor plates of fusion devices, and to 10-km-scale structures of a Lunar surface. We have identified the following new effects: 1) the plasma is absorbed by only a small fraction of the total surface, near the "mountain tops" of the bumps; 2) regions inaccessible for one or both plasma species ("shadows") are formed behind the bumps; the size of these inaccessible domains is, generally speaking, different for the electrons and ions; 3) this latter circumstance leads to formation of fine potential structure both near the surface and in the bulk plasma, leading to enhanced plasma transport. We have investigated the processes that may lead to plasma penetration into the shadows and concluded that most probable candidates are (depending on the specifics of plasma parameters) the lower-hybrid instability and the ionization of the residual gas [5]. Both processes turned out to be relatively slow making the presence of the shadows an almost ubiquitous feature of the problem. 
Formation of the zones inaccessible for the plasma ions and/or electrons particularly important in establishing the distribution of the potential around spacecraft in geomagnetic environment. Development of large electric potentials over the surface of spacecraft may cause arcing and lead to failure of the spacecraft equipment. Fluxes of fast supra-thermal electrons that are usually the primary cause of the charging have to be neutralized by adjustment of the current delivered to the surface by the ambient plasma. However, as the plasma electrons are strongly tied to the magnetic field lines, the zones "shaded" from plasma electrons (and, by virtue of quasi-neutrality, from plasma ions) are formed at some orientation of spacecraft. The charge neutralization of fast electrons gets strongly inhibited in these zones, and large potentials develop. The other type of shadowing occurs if the velocity of the spacecraft is much higher than the ion thermal velocity. In this case, the density of the neutralizing plasma is small outside the zones determined by the Mach angle. We have developed a "three-vector model" [6] that allows one to describe these phenomena in a unified way.

The rate at which the plasma can fill the "shadows" by a mechanism of the type of the lower-hybrid instability is important for all the aforementioned applications, from fusion devices to spacecraft. We have studied this key issue at a small-scale experimental device called "Bluebell", Ref. [7] (we have modified for our purposes the previously existing device, called "Helicon Plasma Source"). The shadowing effect was studied by introducing a collimating mask that allowed to produce plasma streams with radii smaller than the ion gyro-radius. It turned out that these jets persist at distances considerably greater than the initial diameter of the jet $[4,6]$. In other words, the anomalous broadening of the jets, if at all present, is a slow process, and the aforementioned concept of "shadowing" works in its direct form.

To summarize: the results obtained in the course of this work will have an impact on an understanding and improvement of performance of a broad range of laboratory devices and spacecraft.

This work was performed under the auspices of the U.S. Department of Energy by Lawrence Livermore National Laboratory under Contract W-7405-ENG-48 


\section{References (in a chronological sequence)}

1. R.H. Cohen, D.D. Ryutov. "Sheath over a divertor plate with small-scale surface imperfections," 2C-20, International Fusion Theory Conference, Atlanta, March 1998 (UCRL-JC-129678 Abs) - An abstract.

2. R.H. Cohen, D.D. Ryutov. "Sheath over a rough surface in a tilted magnetic field". Phys. Plasmas, v. 5, p. 2194, June 1998 (UCRL-JC-128506) - A refereed journal publication.

3. L.L. Lodestro, T.A. Casper, R.H. Cohen, et al. "Edge and coupled core-edge modeling in tokamaks." 17th IAEA Fusion Energy Conference, October 1998 (UCRL-JC130155) - A conference paper selected by the Program Committee.

4. R.E. Cid, R.H. Cohen, E.B. Hooper, A.W. Molvik, G.D. Porter, D.D. Ryutov. "Experiments on penetration of a plasma with magnetized electrons across a magnetic field." Bull. Am. Phys. Soc., v.43, p.1697, November 1998 (UCRL-JC-131316 Abs) - An abstract.

5. R.H. Cohen, D.D. Ryutov. "Mechanism for penetration of the plasma ions into "shadowed" areas near a non-planar material surface in a magnetic field." Bull. Am. Phys. Soc., v.43, p.1804, November 1998 (UCRL-JC-131316 Abs) - An abstract.

6. G.D. Porter, R.E. Cid, R.H. Cohen, E.B. Hooper, N. Luhmann, A.W. Molvik, D.D. Ryutov. "Three-vector model of formation of potential structures over the surface of spacecraft." American Geophysical Union Transactions, v. 79, \# 45, November 1998 (UCRL-JC-133111 Abs) - An abstract.

7. R.H. Cohen, R. Cid, E.B. Hooper, A.W. Molvik, G.D. Porter, D.D. Ryutov "Sheath over a finely structured divertor plate." To appear in Journ. of Nucl. Materials, March 1999 (UCRL-JC-128903) - A refereed journal publication. 